\title{
Birds in the Daily Life of the Toba Indigenous People from the West of the Province of Formosa (Argentina)
}

Pastor Arenas \& Gustavo Porini. 2009. Tiempo de Historia, Asunción. Pp. 300 + xxvi. \$27.00 (paperback). ISBN 9789995381660

\author{
Reviewed by Gustav F. Scarpa ${ }^{1}$ \\ Reviewer Address: ${ }^{1}$ Centro de Estudios Farmacológicos y Botánicos (CEFYBO-CONICET), Buenos Aires, Argentina
}

Received: July $5^{\text {th }} 2010$

Volume 1:35-36

Published: September $6^{\text {th }} 2010$

(C) 2010 Society of Ethnobiology

This book, whose original title is "Las aves en la vida de los toba del oeste de la provincia de Formosa (Argentina)," is undoubtedly the foundation of Argentinian ethnozoology, since there is as yet no exhaustive monograph on the subject. The authors present the results of an extensive ethno-ornithological research program aimed mainly at knowing how the Toba name, perceive, conceive, use and relate to birds in their natural environment. Once hunter-gatherers and fishermen, Toba are currently experiencing an intensive process of assimilation into the Argentinian way of life. Toba are one of the most populous ethnic groups of the Gran Chaco, the second largest forested region in South America after the Amazon basin.

This subject is part of a broader ethnobiological research program that has been carried out by Pastor Arenas since 1983. The investigation plan was carried out by means of field work consisting of interviews, participant observation, and biological material collection, among other techniques. For the specific subject of birds, these also included bird watching and observation of skins, photographs, and pictures of the local ornithofauna. The information obtained was subsequently organized, analyzed and interpreted, identified, and the biological material was archived in the researcher's cabinet.

Results are presented in two sections: 1) an outline of the diverse cultural and social spheres in which the bird's specific roles are situated, and 2) a species directory which details all the information gathered for each species. The list of chapters is as follows: 1) Preface, 2) Acknowledgements, 3) Introduction, 4) Materials and Methodology, 5) The Toba and their Natural Environment, 6) Birds in the Life of the Toba, 7) Representation of Birds, 8) Usage of Birds, 9) Birds and Subsistence, 10) Material Culture, 11) Other Roles of Birds or their Parts, 12) Nomenclature for Bird
Morphology, 13) Vernacular Names and Classificatory Systems, 14) Bird Directory, 15) The Toba's Knowledge about Birds, 16) Bibliography, 17) Index of Toba and Scientific Names, 18) Index of Scientific and Vernacular Spanish Names.

A fairly complete ethnographic and ecological background is included in the first section of the book to allow the reader to interpret the results adequately. As an example of this, in the chapter The Toba and their Natural Environment, many bird attributes referred to by the people are deeply associated with the annual climatic variability of the region, as well as with the different kinds of habitats these animals occupy. In the same way, most of the subsequent chapters could hardly be understood without taking into account some basic facts related to Toba material culture, mode of subsistence, annual cycle, shamanism and witchcraft, which are outlined briefly by the authors. Utilitarian aspects of birds are described in such a manner as to avoid repetitions in the second part of the book, where data is presented and arranged by bird species. The uses of birds in material culture, both as medicines and especially as announcers, are highlighted. In fact, birds are considered the main announcing agents for the Toba; birds advertise goodness, including some important economic resources such as game animals and fishes, and evilness, such as harmful spirits of malicious shamans or witches. This is the case of the frightening po'tanagae (Crotophaga ani, Cuculidae) whose singing is a clear sign of witchcraft activities and who always announces death. People of ancient times run immediately when they heard it near the villages; nowadays, they shoot them whenever they can.

The detailed analysis of bird morphology made on the basis of Toba knowledge constitutes another very interesting part of the book, which reveals aspects linked to perception and representation of these 
animals. These details are shown in a comprehensive manner through schematic and beautiful drawings of each kind of bird. The first section of the book ends by looking in even greater depth at the significance of birds for Toba, identifying and analyzing the vernacular nomenclature. As a corollary of this analysis, a preliminary model of the vernacular classificatory system of birds is proposed here, giving a useful approximation to the Toba view of the avian world in a cognitively structured manner.

The last section of the book includes the description of uses and general representations of birds in Toba's daily life, for each one of the 169 native and naturalized taxons, 7 domesticated exotic species, and 20 ornithological entities that authors have been unable to identify. Ma'ñik, the American ostrich (Rhea americana, Rheidae), is the most outstanding avian species for the Toba, not only as a primary source of food but also for the multiple connotations it has in social life. In order to secure the position needed to strike ostrich with an arrow in open fields, the Toba wear an amazing camouflage made with lianas and leafy shrubs interweaved all around their bodies.

Drawings, graphics and photographs illustrate many species. The amount of information gathered on this matter clearly shows that these animals have been and still are of great importance for these people. Bird songs and behaviors, as well as their feathers, eggs, bones and meat, among other features, have ample implications and meanings for the life of the Toba. 